\title{
AMMONIUM NITRATE AS AN OXIDIZER IN SOLID COMPOSITE PROPELLANTS
}

\author{
G. B. Manelis and D. B. Lempert
}

\begin{abstract}
Despite the fact that ammonium nitrate (AN) has the highest hydrogen content and fairly high oxygen balance (compared to other oxidizers), its extremely low formation enthalpy and relatively low density makes it one of the worst power oxidizers in solid composite propellants (SCP). Nevertheless, AN has certain advantages - the combustion of the compositions containing AN is virtually safe, its combustion products are ecologically clean, it is very accessible and cheap, and also very thermostable (far more stable than ammonium dinitramide (ADN)). Besides, its low density stops being a disadvantage if the propellant has to be used in deep space and therefore, must be carried there with other rocket carriers. The low cost of AN may also become a serious advantage in the AN application even in lower stages of multistage space launchers as well as in one-stage space launchers with low mass fraction of the propellant. The main specific features relevant to the creation of AN-based SCPs with the optimal energetic characteristics are discussed. The use of metals and their hydrides and proper fuel-binders as well as the recent successes in phase stabilization of AN are described.
\end{abstract}

\section{INTRODUCTION}

Ammonium nitrate is the cheapest and most available oxidizer for SCPs. It was AN that the early solid propellants were based on. Ammonium nitrate combines a favorable element composition (5\% hydrogen, $60 \%$ oxygen, absence of halides), high thermal stability, and sufficient compatibility with a number of other constituents. However, its low enthalpy of formation $(-4514 \mathrm{~kJ} / \mathrm{kg})$ and relatively low density $\left(1.725 \mathrm{~g} / \mathrm{cm}^{3}\right)$ make AN not competitive in energy potential to a majority of other known oxidizers.

Still, the attractive features of AN (environmentally friendly combustion products, low cost, very low sensitivity to mechanical loading, high thermal stability) can revive interest to this oxidizer for the applications with special requirements. 


\section{THE OBJECTS AND CRITERIA FOR COMPARISON}

In this work, the energetic potential of AN-based SCPs are compared with analogous formulations based on the more frequently used oxidizers: ammonium perchlorate (AP) and ADN. All thermodynamic calculations for the specific impulse $\left(I_{\mathrm{sp}}\right)$ were performed for the combustion chamber pressure $\left(P_{c}\right)$ of 40 bar and at the nozzle exit pressure $\left(P_{a}\right)$ of 1 bar. Since these three oxidizers have different density (AP - 1.95; ADN - 1.80-1.82; and $\mathrm{AN}-1.725 \mathrm{~g} / \mathrm{cm}^{3}$ ) and the propellant density $(\rho)$ substantially affects the ballistics, the formulations were compared not only by $I_{\mathrm{sp}}$ but also by the so-called ballistic efficiency. In this paper, the ballistic efficiency [1] of the $i$ th launcher stage $\left(E_{i}\right)$ defined as $E_{1}=I_{\mathrm{sp}} \rho^{0.6} ; E_{2}=I_{\mathrm{sp}} \rho^{0.4}$; and $E_{3}=I_{\mathrm{sp}} \rho^{0.2}$ is considered. The exponents values $(0.2,0.4$, and 0.6$)$ correspond to three-stage rocket launchers with optimized stage masses and tank volumes of every stage. Using these equations, one can affirm that, e.g., if there are two different propellants (the first one possessing $I_{\mathrm{sp} 1}$ and $\rho_{1}$ while the second one possessing $I_{\mathrm{sp} 2}$ and $\rho_{2}$ ), the usage of the first propellant in the first stage would provide a higher speed growth than the usage of the second propellant (propellants used in the 2nd and 3rd stages being equal) if $I_{\mathrm{sp}_{1}} \rho_{1}^{0.6}>I_{\mathrm{sp}_{2}} \rho_{2}^{0.6}$. Naturally, the density exponents depend on the volume-to-mass ratio for each stage and can differ substantially. Since AN has lower density than ADN and AP, its efficiency is worst for the first stage.

The choice of a binder is important to materialize the potential of oxidizers. Four different binders were used in the calculations, namely:

(1) hydrocarbon binder (HB), $\Delta H_{f}=-390 \mathrm{~kJ} / \mathrm{kg}, \rho=0.91 \mathrm{~g} / \mathrm{cm}^{3}$, hydrogen content $\sim 12 \%$;

(2) poly(methylvinyltetrazole) (PMVT) - $\left(\mathrm{C}_{4} \mathrm{~N}_{4} \mathrm{H}_{6}\right)_{n}$, a high-enthalpy polymer with high content of nitrogen $(\sim 46 \%), \Delta H_{f}=+1255 \mathrm{~kJ} / \mathrm{kg}, \rho=$ $1.28 \mathrm{~g} / \mathrm{cm}^{3}$;

(3) active binder (AB), a model binder analogous to practical ones, $20 \%$ pol$\mathrm{y}$ (vinylmethyltetrazole), plasticized with a mixture of trinitroglycerol with 2,4-dinitro-2,4-diazo-pentane; its gross formula is close to $\mathrm{C}_{19} \mathrm{H}_{34,5} \mathrm{~N}_{19} \mathrm{O}_{29,5}$; $\Delta H_{f}=-757 \mathrm{~kJ} / \mathrm{kg}, \rho=1.49 \mathrm{~g} / \mathrm{cm}^{3}$, oxygen content $\sim 47 \%$; and

(4) poly(vinylmethoxydiazen-N-oxide) (PVMDO) $\left(\mathrm{C}_{3} \mathrm{H}_{6} \mathrm{~N}_{2} \mathrm{O}_{2}\right)_{n}, \Delta H_{f}=$ $0 \mathrm{~kJ} / \mathrm{kg}, \rho=1.31 \mathrm{~g} / \mathrm{cm}^{3}$, a model binder rich in hydrogen $(\sim 6 \%)$ and oxygen $(\sim 31 \%)$. 


\section{ENERGY POTENTIAL OF THE FORMULATIONS}

Formulations containing energetic components (aluminum, beryllium, or aluminum hydride $(\mathrm{AH})$ ) and simple pairs of oxidizer + binder were considered. The lower the formation enthalpy of an oxidizer, the more the oxidizer needs an additive of energetic component [2]. For the sake of brevity, only the calcu-

Table 1 Energy potential of metal-free formulations

\begin{tabular}{|c|c|c|c|c|c|c|c|c|c|}
\hline \multirow{2}{*}{ Oxidizer } & \multicolumn{2}{|c|}{ Binder } & \multirow{2}{*}{$\begin{array}{c}I_{\mathrm{sp}}, \\
\mathrm{s}\end{array}$} & \multirow{2}{*}{$\begin{array}{c}\rho, \\
\mathrm{g} / \mathrm{cm}^{3}\end{array}$} & \multirow{2}{*}{$\begin{array}{c}T_{c} \\
\mathrm{~K}\end{array}$} & \multirow{2}{*}{$\begin{array}{c}T_{a}, \\
\mathrm{~K}\end{array}$} & \multirow{2}{*}{$E_{1}$} & \multirow{2}{*}{$\begin{array}{c}E_{2}, \\
\mathrm{~cm}^{3}, \mathrm{~s}\end{array}$} & \multirow[t]{2}{*}{$E_{3}}$, \\
\hline & $\%$ (wt.) & $\%$ (vol.) & & & & & & & \\
\hline \multirow{3}{*}{$\mathrm{AB}+\mathrm{AN}$} & 25 & 27.8 & 219.3 & 1.660 & 2440 & 1297 & 297.2 & 268.6 & 242.7 \\
\hline & 26 & 28.9 & 221.2 & 1.657 & 2476 & 1327 & 299.5 & 270.7 & 244.7 \\
\hline & 27 & 30.0 & 223 & 1.655 & 2511 & 1358 & 301.7 & 272.8 & 246.6 \\
\hline \multirow[b]{2}{*}{$\mathrm{HB}+\mathrm{AN}$} & 10.5 & 18.2 & 209.8 & 1.577 & 2017 & 998 & 275.7 & 251.7 & 229.8 \\
\hline & 11 & 19.0 & 208.5 & 1.570 & 1976 & 974 & 273.3 & 249.7 & 228.2 \\
\hline \multirow{3}{*}{$\mathrm{PMVT}+\mathrm{AN}$} & 13 & 16.8 & 18.3 & 1.650 & 2348 & 1200 & 294.9 & 266.7 & 241.3 \\
\hline & 14 & 18.0 & 217.1 & 1.645 & 2309 & 1172 & 292.7 & 264.9 & 239.8 \\
\hline & 15 & 19.2 & 215.8 & 1.640 & 2268 & 1143 & 290.3 & 263.0 & 238.2 \\
\hline \multirow{3}{*}{$\mathrm{PVMDO}+\mathrm{AN}$} & 14 & 17.7 & 221.5 & 1.652 & 2408 & $\overline{1276}$ & 299.3 & 270.7 & $\overline{244.9}$ \\
\hline & 15 & 18.9 & 224.9 & 1.647 & 2460 & 1329 & 303.4 & 274.6 & 248.5 \\
\hline & 16 & 20.1 & 226.3 & 1.642 & 2490 & 1338 & 304.7 & 275.9 & 249.9 \\
\hline \multirow{4}{*}{$\mathrm{AB}+\mathrm{AP}$} & 25 & 30.4 & 4.8 & 1.81 & 2663 & 1457 & 306.7 & 272.4 & 241.9 \\
\hline & 26 & 31.5 & 6.7 & 1.805 & 2697 & 1490 & 308.9 & 274.4 & 243.9 \\
\hline & 27 & 32.6 & 218.5 & 1.800 & 2730 & 1525 & 310.9 & 276.4 & 245.8 \\
\hline & 28 & 33.7 & 220.4 & 1.79 & 2762 & 1560 & 313.1 & 278.5 & 247.8 \\
\hline \multirow{3}{*}{$\mathrm{HB}+\mathrm{AP}$} & 9. & 18.4 & 39.8 & 1.7 & 2989 & 1953 & 336.5 & 300.6 & 268.5 \\
\hline & 10 & 19.2 & 0.6 & 1.7 & 3003 & 1910 & 336.6 & 301.0 & 269.1 \\
\hline & 11 & 20.9 & 240.5 & 1.732 & 3007 & 1793 & 334.4 & 299.6 & 268.4 \\
\hline \multirow{3}{*}{$\mathrm{PMVT}+\mathrm{AP}$} & 20 & 27.6 & $\overline{238.2}$ & 1.765 & 3004 & 1770 & 335.0 & $\begin{array}{l}299.0 \\
\end{array}$ & $\overline{266.9}$ \\
\hline & 21 & 28.8 & 234.7 & 1.757 & 2994 & 1709 & 329.1 & 294.0 & 262.7 \\
\hline & 22 & 30.1 & 236.5 & 1.749 & 2975 & 1651 & 330.7 & 295.7 & 264.5 \\
\hline \multirow{2}{*}{$\mathrm{PVMDO}+\mathrm{AP}$} & 22 & 29.6 & 239.7 & 1.761 & 3005 & 1927 & $\overline{336.6}$ & 300.6 & 268.4 \\
\hline & 23 & 30.8 & 241.8 & 1.753 & 3025 & 1983 & 338.6 & 302.7 & 270.5 \\
\hline \multirow{2}{*}{$\mathrm{AB}+\mathrm{ADN}$} & 26 & 30.0 & 39.3 & 1.721 & 2930 & 1714 & $\overline{331.4}$ & 297.3 & 266.7 \\
\hline & 27 & 31.1 & 240.6 & 1.717 & 2950 & 1743 & 332.8 & 298.7 & 268.1 \\
\hline \multirow[b]{2}{*}{$\mathrm{HB}+\mathrm{ADN}$} & 10 & 18.2 & 250.9 & 1.655 & 3017 & 1660 & $\overline{339.4}$ & 306.9 & 277.5 \\
\hline & 11 & 19.8 & 249 & 1.640 & 2967 & 1580 & 335.0 & 303.5 & 274.9 \\
\hline \multirow{3}{*}{$\mathrm{PMVT}+\mathrm{ADN}$} & 14 & 17.5 & 250 & 1.596 & 3025 & 1894 & $\overline{331.0}$ & 301.4 & $\overline{274.5}$ \\
\hline & 15 & 18.5 & 250.4 & 1.5 & 3038 & 1833 & 329.8 & 300.9 & 274.5 \\
\hline & 16 & 19.6 & 250 & 1.569 & 3043 & 1774 & 327.6 & 299.4 & 273.6 \\
\hline \multirow{3}{*}{$\mathrm{PVMDO}+\mathrm{ADN}$} & 20 & 25.8 & 254 & $1.6 \xi$ & 3073 & 1945 & 347.8 & 313.2 & 282.1 \\
\hline & 21 & 27.0 & 254.3 & 1.682 & 3082 & 1904 & 347.5 & 313.1 & 282.2 \\
\hline & 22 & 28.2 & 254.3 & 1.676 & 3088 & 1865 & 346.7 & 312.7 & 282.0 \\
\hline
\end{tabular}


Table 2 Energy potential of the formulations with $20 \% \mathrm{Al}$

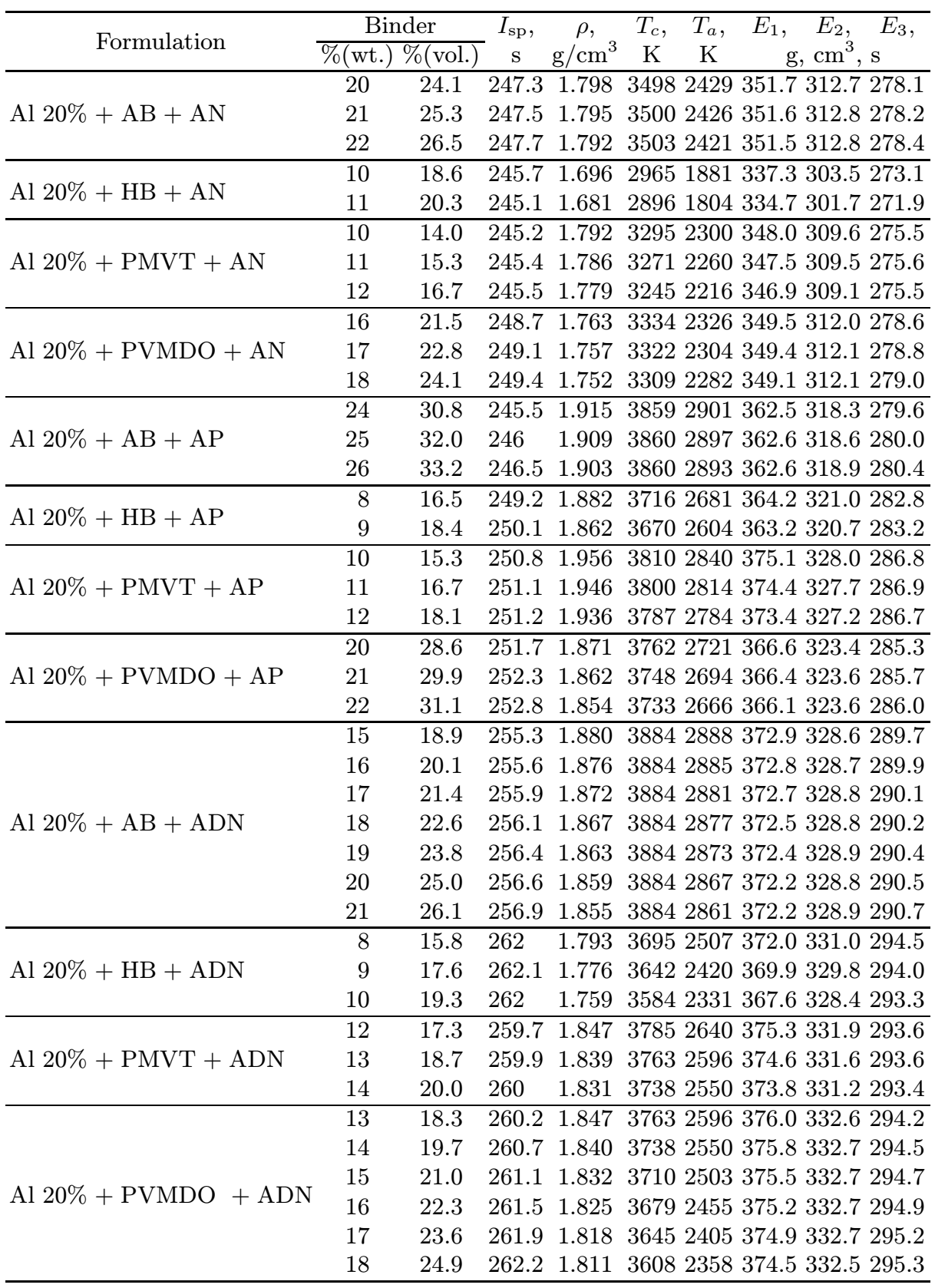


Table 3 Energy potential of the formulations with $13 \%$ Be

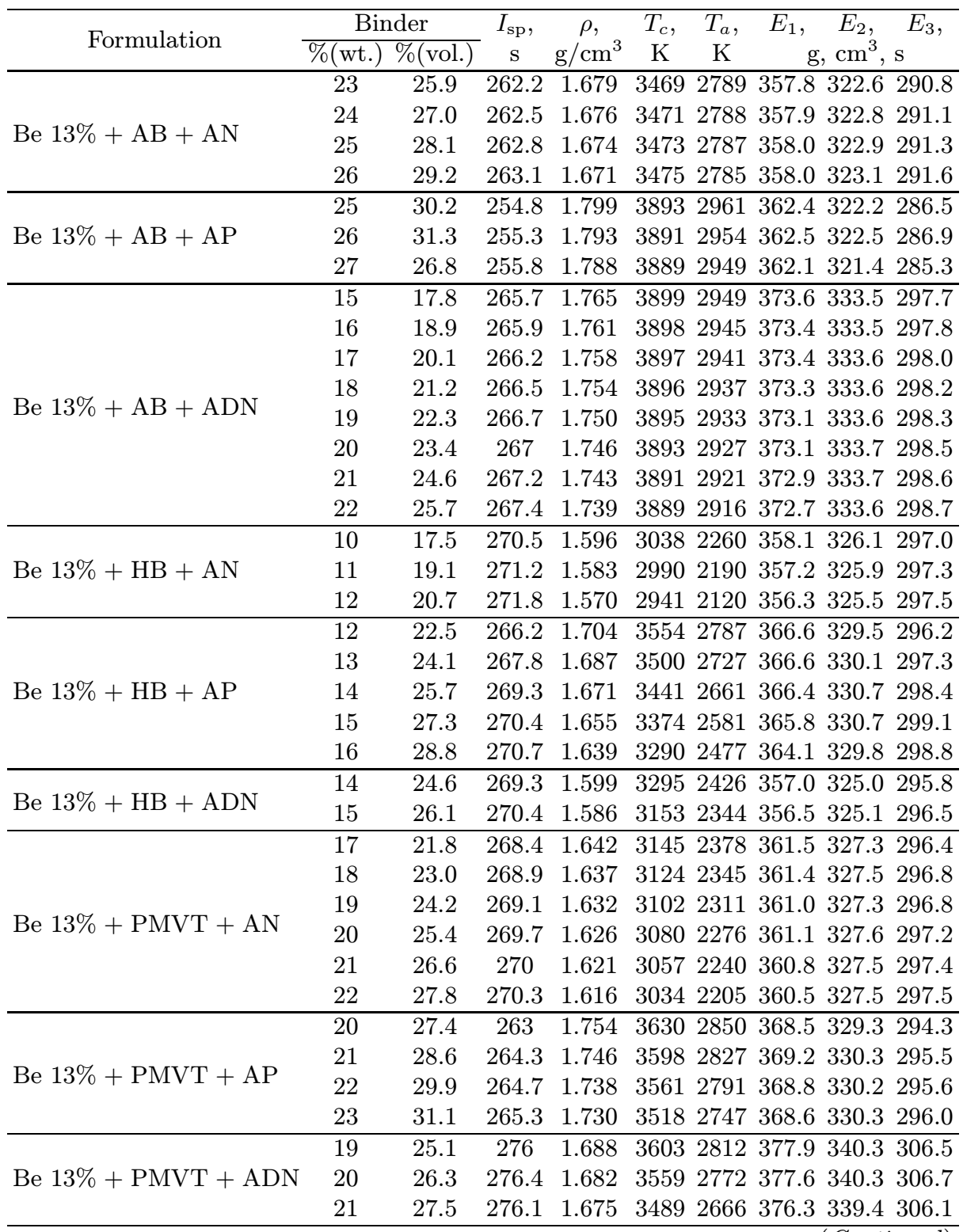


Table 3 Energy potential of the formulations with $13 \%$ Be (Continued)

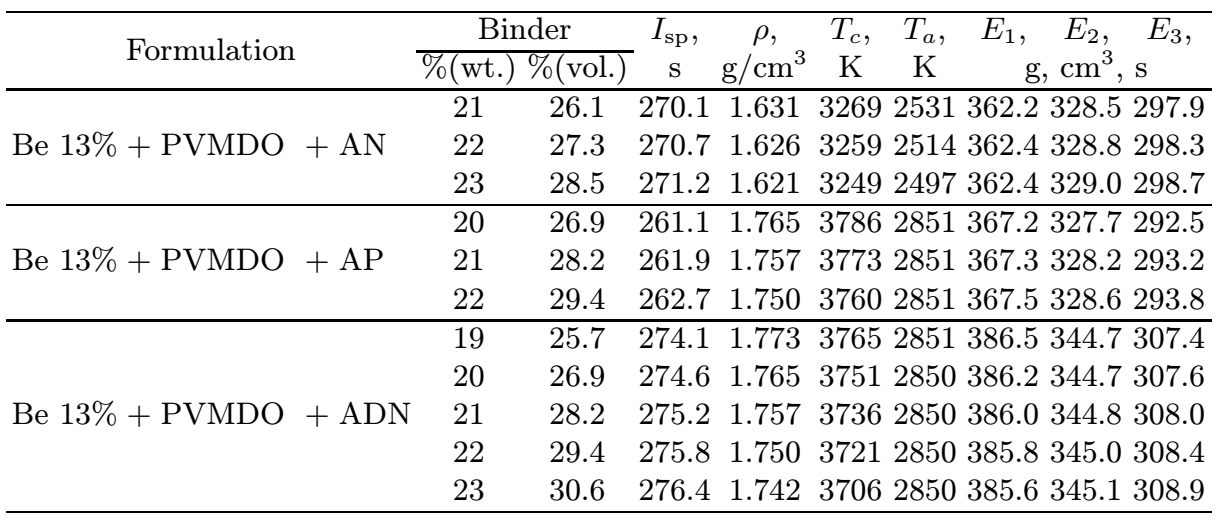

lated data for the formulations with a constant content of energetic component, $20 \% \mathrm{Al}, 13 \% \mathrm{Be}$, or $25 \% \mathrm{AlH}_{3}$ are presented herein. At these concentrations, the formulations are close to optimal in energy, although it is known that, owing to two-phase losses, higher stages require a somewhat lower metal content. Tables 1 to 5 and Figs. 1 to 8 present the main results of the calculations.

The calculations were performed for a widely varied content of binders. Tables 1 to 3 show the formulations with the binder fraction exceeding 18-19\%(vol.) (at lower content of binders, a formulation with satisfactory mechanical properties cannot be obtained).

Figures 1 to 12 show that for the active binder and PVMDO, possessing relatively high oxygen content, the optima in $I_{\mathrm{sp}}$ and $E_{i}$ are achieved at a higher volume content of binders as compared to the hydrocarbon binder and PMVT. Table 4 summarizes the maximum attainable $E_{i}$, provided the volume fraction of a binder is not less than $19 \%$.

A careful analysis of the results shows that in metal-free compositions, $\mathrm{AN}$ is inferior to AP and ADN for all launcher stages. Introduction of aluminum, and even more so beryllium, substantially decreases the loss. The higher the stage, the better AN performs compared to AP and ADN. For the 3rd stage, AN is not worse than AP and only a little worse than ADN.

The use of $\mathrm{AH}$ in the formulations with $\mathrm{AB}$ (the other binders are substantially less efficient with $\mathrm{AH}$ ) results in the enhancement of $E_{2}$ and $E_{3}$ over the corresponding values for the formulations based on aluminum (with any binder). $\mathrm{AlH}_{3}$ values become close to those for Be-containing formulations. Table 5 shows the calculated data. The binder content of the formulations with $\mathrm{AH}$ must be substantially higher compared to the metal-based formulations because the small hydride particles have large surface area, and the formulations with the binder 
Table 4 Maximum attainable $E_{i}$ for different compositions

\begin{tabular}{|c|c|c|c|c|}
\hline \multirow{2}{*}{ Oxidizer } & \multicolumn{4}{|c|}{ Binder } \\
\hline & HB & $\overline{\mathrm{AB}}$ & $\overline{\mathrm{PMVT}}$ & PVMDO \\
\hline \multicolumn{5}{|c|}{ Metal-free $-E_{1}$} \\
\hline $\mathrm{AN}$ & 272 & 300 & 293 & 303 \\
\hline $\mathrm{AP}$ & 335 & 310 & 338 & 335 \\
\hline $\mathrm{ADN}$ & 335 & 335 & 331 & 345 \\
\hline \multicolumn{5}{|c|}{ Metal-free $-E_{2}$} \\
\hline $\mathrm{AN}$ & 250 & 275 & 262 & 275 \\
\hline AP & 300 & 275 & 299 & 300 \\
\hline $\mathrm{ADN}$ & 305 & 298 & 301 & 311 \\
\hline \multicolumn{5}{|c|}{ Metal-free $-E_{3}$} \\
\hline $\mathrm{AN}$ & 224 & 248 & 238 & 250 \\
\hline $\mathrm{AP}$ & 264 & 245 & 268 & 270 \\
\hline $\mathrm{ADN}$ & 278 & 268 & 274 & 283 \\
\hline \multicolumn{5}{|c|}{$20 \% \mathrm{Al}-E_{1}$} \\
\hline $\mathrm{AN}$ & 337 & 354 & 345 & 350 \\
\hline AP & 363 & 362 & 372 & 366 \\
\hline $\mathrm{ADN}$ & 368 & 372.5 & 374 & 375 \\
\hline \multicolumn{5}{|c|}{$20 \% \mathrm{Al}-E_{2}$} \\
\hline $\mathrm{AN}$ & 303 & 312.5 & 308 & 312 \\
\hline $\mathrm{AP}$ & 321 & 315.5 & 326 & 321 \\
\hline $\mathrm{ADN}$ & 328 & 327 & 331 & 332 \\
\hline \multicolumn{5}{|c|}{$20 \% \mathrm{Al}-E_{3}$} \\
\hline $\mathrm{AN}$ & 272 & 278 & 275 & 278 \\
\hline $\mathrm{AP}$ & 283 & 275 & 286 & 280 \\
\hline $\mathrm{ADN}$ & 293 & 291 & 293 & 294 \\
\hline \multicolumn{5}{|c|}{$13 \% \mathrm{Be}-E_{2}$} \\
\hline$\overline{\mathrm{AN}}$ & 326 & 322 & 327 & 329 \\
\hline $\mathrm{AP}$ & 331 & 321 & 330 & 328 \\
\hline $\mathrm{ADN}$ & 323 & 333 & 340 & 344 \\
\hline \multicolumn{5}{|c|}{$13 \% \mathrm{Be}-E_{3}$} \\
\hline $\mathrm{AN}$ & 297.5 & 291 & 297 & 295 \\
\hline AP & 299 & 287 & 296 & 298 \\
\hline $\mathrm{ADN}$ & 296.5 & 299 & 307 & 308 \\
\hline
\end{tabular}

content less than $28 \%-33 \%$ do not exhibit satisfactory physicomechanical and rheological properties.

Table 6 summarizes the calculated maximum attainable $E_{2}$ and $E_{3}$ performances. These data are also presented in Fig. 13.

The above data show that upon the replacement of $\mathrm{Al}$ with $\mathrm{AlH}_{3}$ or $\mathrm{Be}$, the maximum attainable $E_{2}$ and $E_{3}$ become less sensitive to the oxidizer na- 
Table 5 Energy potential of the formulations with $\mathrm{AH}(25 \%)$ and the $\mathrm{AB}$

\begin{tabular}{|c|c|c|c|c|c|c|c|c|}
\hline \multirow{2}{*}{ Formulation } & \multicolumn{2}{|c|}{ Binder } & \multirow{2}{*}{$\begin{array}{c}I_{\mathrm{sp}} \\
\mathrm{s}\end{array}$} & \multirow{2}{*}{$\begin{array}{c}\rho, \\
\mathrm{g} / \mathrm{cm}^{3}\end{array}$} & \multirow{3}{*}{$\begin{array}{c}T_{c}, \\
\mathrm{~K} \\
3208\end{array}$} & \multirow{2}{*}{$\begin{array}{c}T_{a} \\
\mathrm{~K}\end{array}$} & \multirow{2}{*}{\multicolumn{2}{|c|}{$\begin{array}{c}E_{1}, E_{2}, \quad E_{3}, \\
\mathrm{~g}, \mathrm{~cm}^{3}, \mathrm{~s}\end{array}$}} \\
\hline & $\%$ (wt.) & $\%$ (vol.) & & & & & & \\
\hline \multirow{3}{*}{$\mathrm{AlH}_{3} 25 \%+\mathrm{AB}+\mathrm{AN}$} & 25 & 26.8 & 267.4 & 1.596 & & 2125 & $\begin{array}{lll}354.0 & 322.4\end{array}$ & 293.6 \\
\hline & 27 & 28.8 & 267.6 & 1.591 & 3206 & 2117 & $\begin{array}{lll}353.6 & 322.3\end{array}$ & 293.7 \\
\hline & 29 & 30.9 & 267.9 & 1.587 & 3204 & 2109 & $\begin{array}{lll}353.4 & 322.2\end{array}$ & 293.8 \\
\hline \multirow{3}{*}{$\mathrm{AlH}_{3} 25 \%+\mathrm{AB}+\mathrm{ADN}$} & 25 & 27.4 & 277.6 & 1.636 & 3564 & 2345 & 372.9338 .0 & 306.3 \\
\hline & 27 & 29.5 & 277.4 & 1.629 & 3548 & 2327 & $\begin{array}{lll}371.8 & 337.2\end{array}$ & 305.8 \\
\hline & 28 & 30.6 & 277.4 & 1.626 & 3540 & 2327 & $\begin{array}{lll}371.3 & 336.9\end{array}$ & 305.7 \\
\hline \multirow{3}{*}{$\mathrm{AlH}_{3} 25 \%+\mathrm{AB}+\mathrm{AP}$} & 25 & 28.3 & 270.3 & 1.686 & 3589 & $\overline{2466}$ & 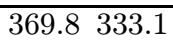 & 300.1 \\
\hline & 27 & 30.4 & 270.5 & 1.677 & 3573 & 2438 & 368.9332 .6 & 300.0 \\
\hline & 29 & 32.5 & 270.8 & 1.668 & 3557 & 2410 & $\begin{array}{lll}368.1 & 332.3\end{array}$ & 300.0 \\
\hline
\end{tabular}

ture, although the order of relative efficiency of the oxidizers remains the same: $\mathrm{ADN}>\mathrm{AP}>\mathrm{AN}$.

The use of AN instead of AP and ADN can be justified in systems where the overall content of oxidizers is low, e.g., in the formulations based on the AB with a high content of HMX (usually, 50\%-55\%, whereas AP content amounts to $\sim 10 \%$ ). Since further increase of HMX content deteriorates combustion properties, one should replace AP with AN at the expense of a minor loss in energy potential (Table 7). Such formulations become environmentally safe as compared to AP-based propellants and much more thermally stable than the ADN-based propellants. These AN formulations surpass AP in energy potential and are virtually the same as the ADN-based formulations.

\section{STABILITY OF AMMONIUM NITRATE, ITS COMPATIBILITY WITH OTHER COMPONENTS OF SOLID COMPOSITE PROPELLANTS, AND THE PROBLEM OF PHASE STABILITY}

Ammonium nitrate is a sufficiently stable compound. The rate constant [3] for its solid-phase decomposition (i.e., below $166{ }^{\circ} \mathrm{C}$ ) is

$$
k=2.2 \cdot 10^{12} \exp \left(-\frac{45,000}{R T}\right), \mathrm{s}^{-1} ;
$$

so, even at $140{ }^{\circ} \mathrm{C}, k=3.4 \cdot 10^{-12} \mathrm{~s}^{-1}$. This stability exceeds by orders of magnitude general requirements. The thermal decomposition proceeds via the 

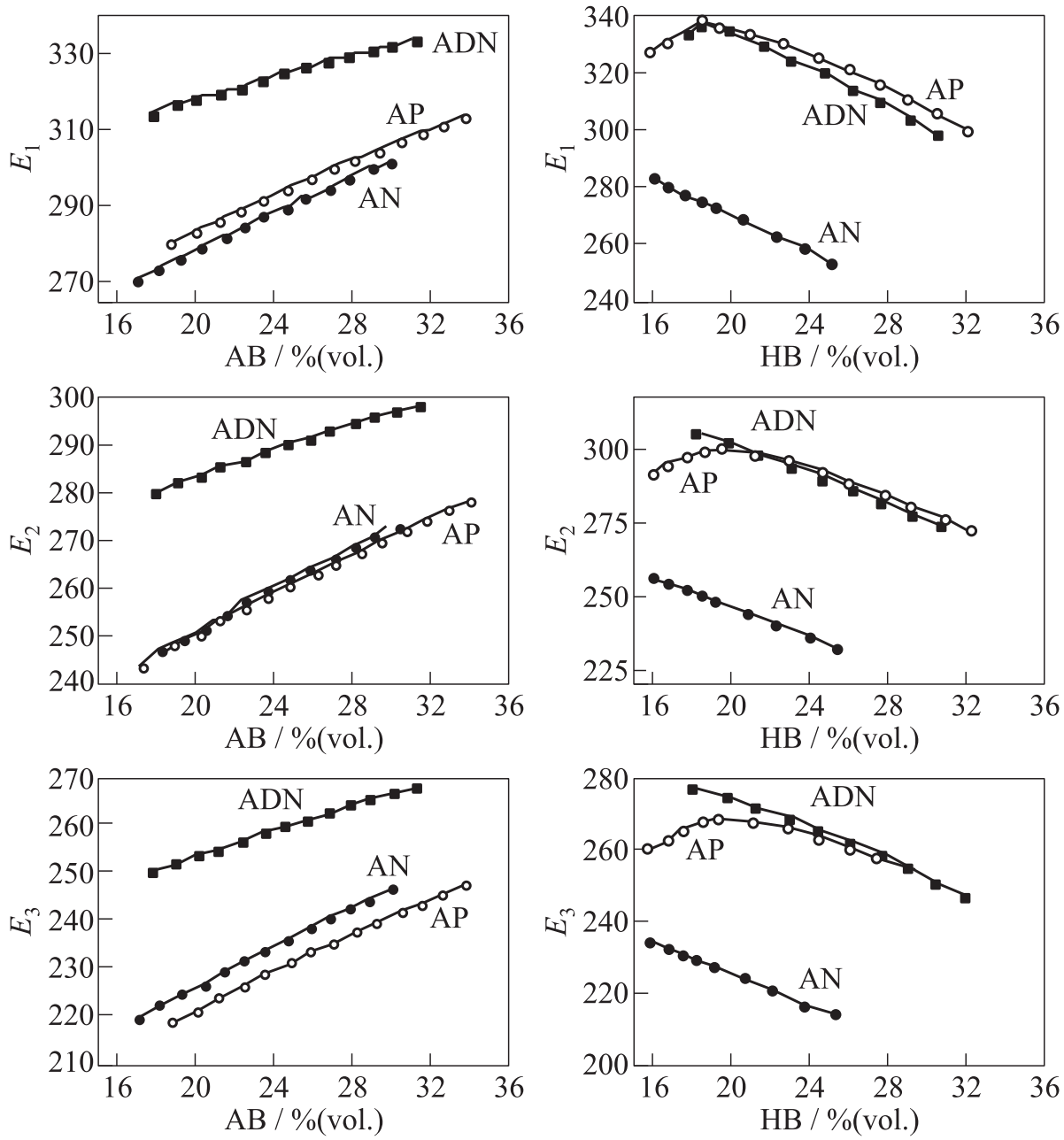

Figure 1 Ballistic efficiency of $\mathrm{AB}$ + oxidizer compositions

Figure 2 Ballistic efficiency of HB + oxidizer compositions

salt dissociation with the formation of free nitric acid. Therefore, a compound having acidic nature, e.g., oxalic acid, catalyzes AN decomposition. This catalysis depends upon various properties, in particular, upon component acidity, e.g., organic acids that are considerably weaker than oxalic do not affect AN decomposition [4]. To date, the stability of AN-based formulations (if one means that "stability" is the "absence of other substances formation") is a solved problem. 

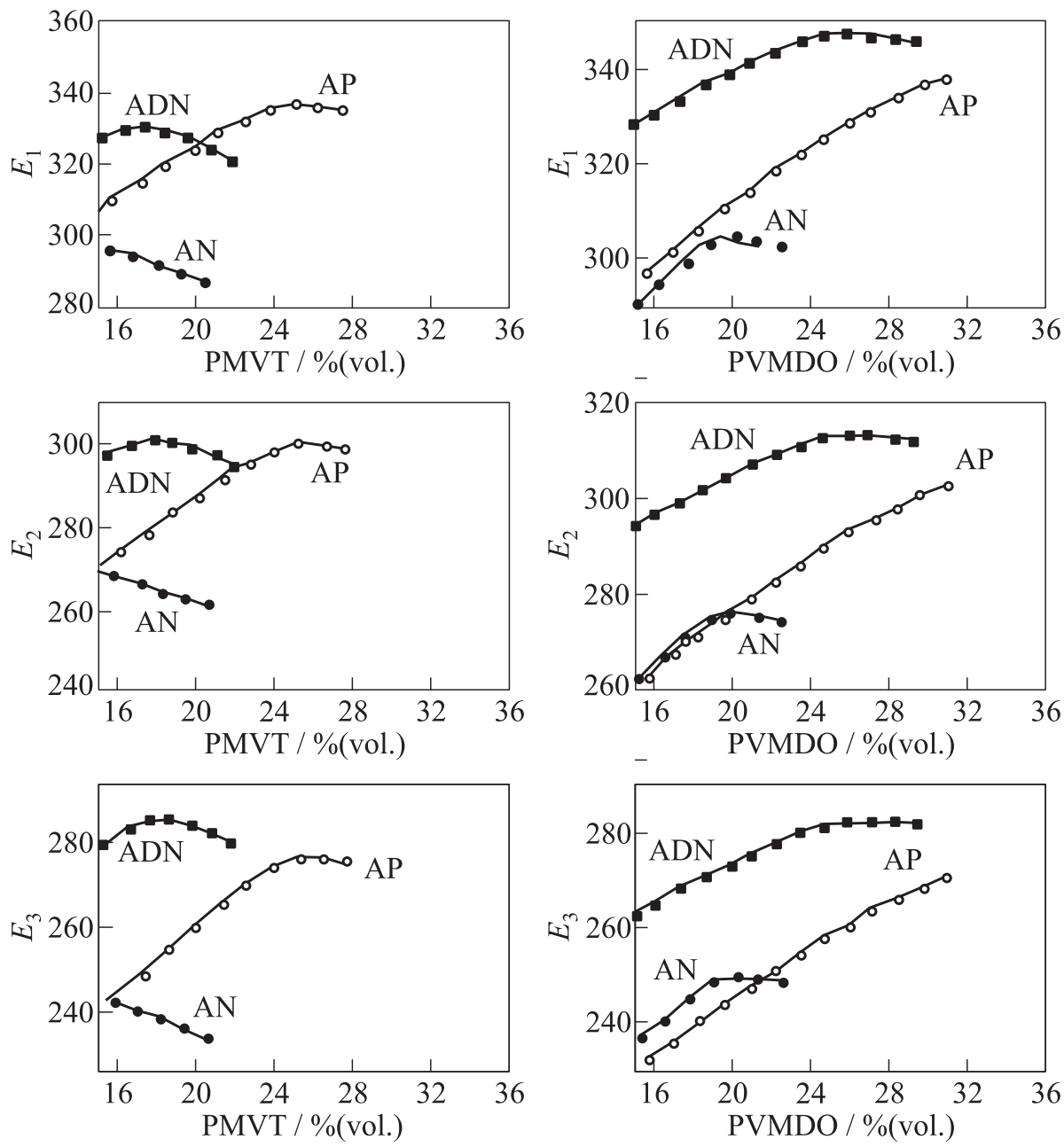

Figure 3 Ballistic efficiency of PMVT + oxidizer compositions

Figure 4 Ballistic efficiency of PVMDO + oxidizer compositions

However, AN has a specific drawback, i.e., the occurrence of three-phase transitions accompanied by changes in density in the temperature range of normal solid propellant operation (V-IV transition at $-17{ }^{\circ} \mathrm{C}$, IV-III at $+32{ }^{\circ} \mathrm{C}$, and III-II at $+82{ }^{\circ} \mathrm{C}$ ). These transitions cause mechanical degradation of propellants during storage. A known method to suppress these phase transitions is to add over $8 \%$ potassium nitrate [5]. A number of studies aimed at phase stabilization 

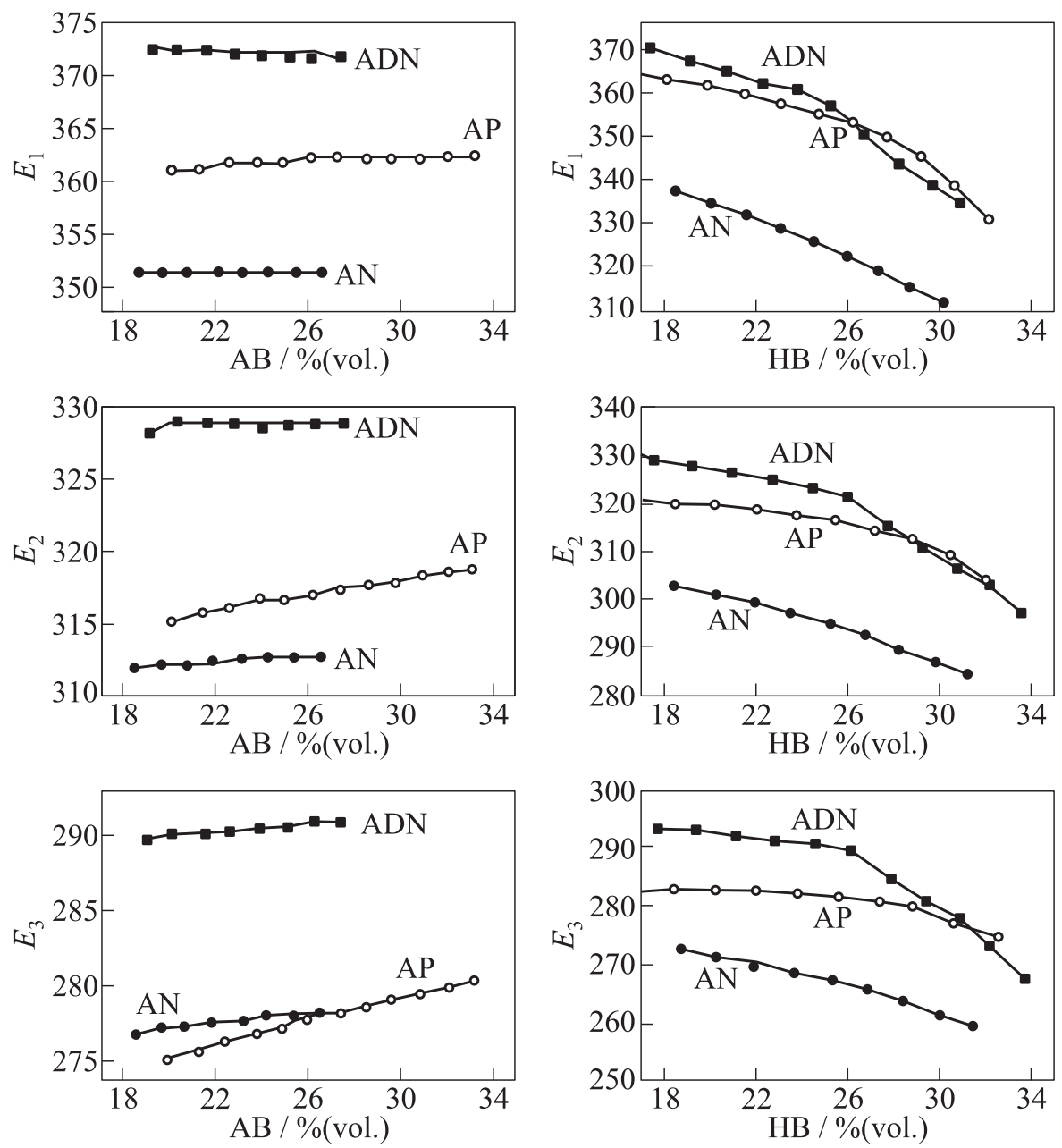

Figure 5 Ballistic efficiency of $\mathrm{AB}$ + oxidizer $+20 \% \mathrm{Al}$ compositions

Figure 6 Ballistic efficiency of $\mathrm{HB}$ + oxidizer $+20 \% \mathrm{Al}$ compositions

of AN with additives that contain neither metals nor halides were performed by the present authors. It seemed possible to achieve stabilization by introducing anions of close dimensions into AN lattice. However, the choice of anions commensurate with the nitrate is limited; $\mathrm{NO}_{2}^{-}$and $\mathrm{CO}_{3}^{-2}$ do not fit due to poor stability of ammonium nitrite and carbonate. Azide, cyanate, and oxalate anions could not be introduced into AN lattice by alloying or by crystallization from solution. This occurs apparently due to substantial differences in the anion 

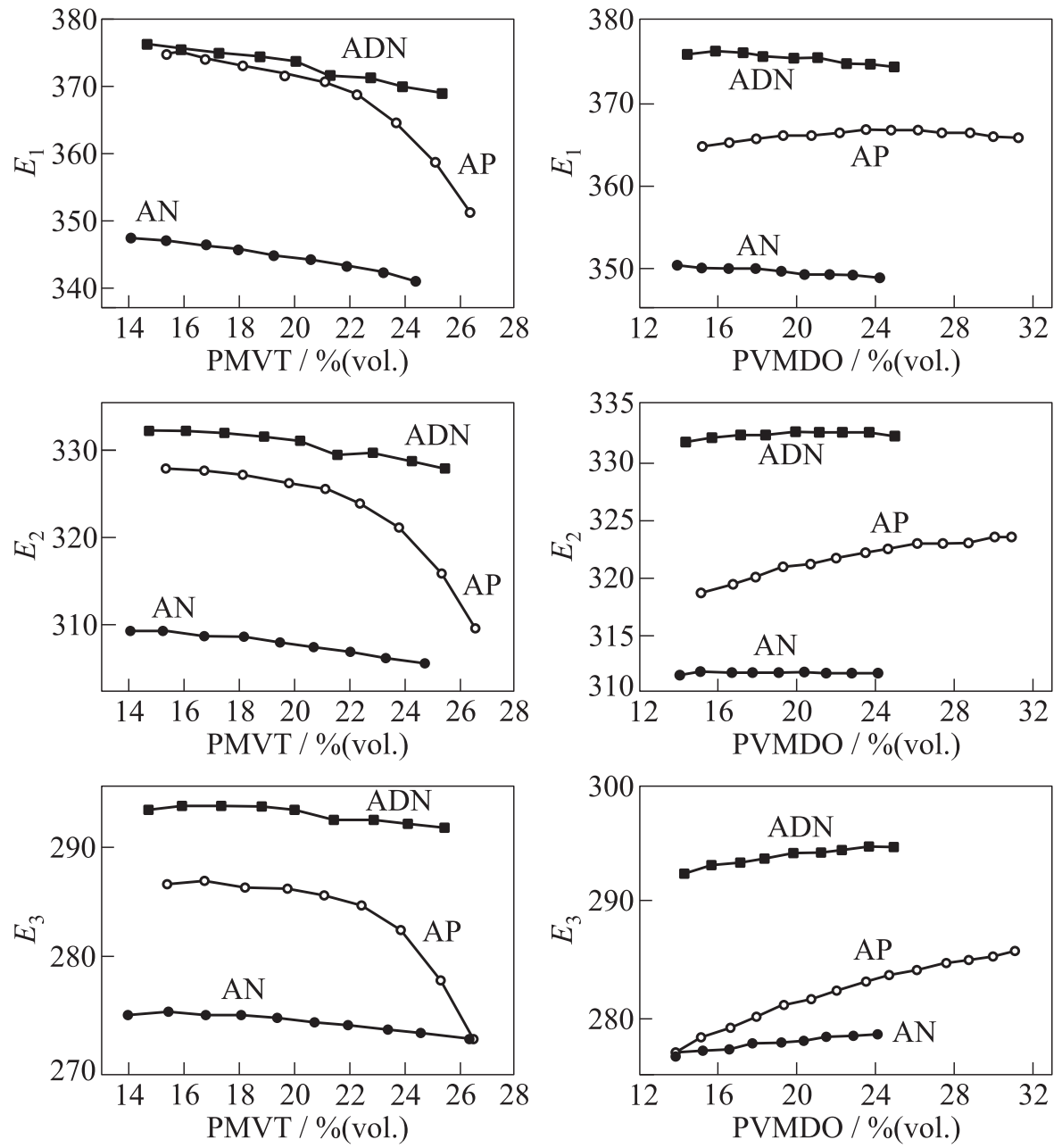

Figure 7 Ballistic efficiency of PMVT + oxidizer $+20 \% \mathrm{Al}$ compositions

Figure 8 Ballistic efficiency of PVMDO + oxidizer $+20 \% \mathrm{Al}$ compositions

structure. Only formate anion proved capable of forming isomorphous alloys in AN lattice in both cocrystallization and alloying [6]. Unfortunately, the phase stabilization could be achieved only at a high content of formate, so the resulting compound made little sense as an oxidizer. Authors' studies showed that a number of compounds, namely, derivatives of five- or six-member nitrogen-containing heterocycles with carbonyl, amine, or imine groups, have a stabilizing effect on 

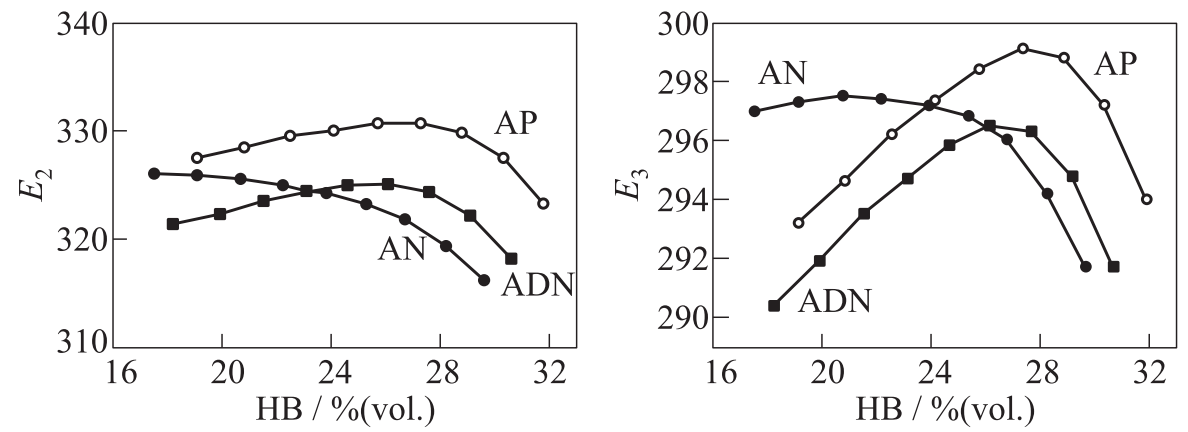

Figure 9 Ballistic efficiency of $\mathrm{HB}+$ oxidizer $+13 \%$ Be compositions
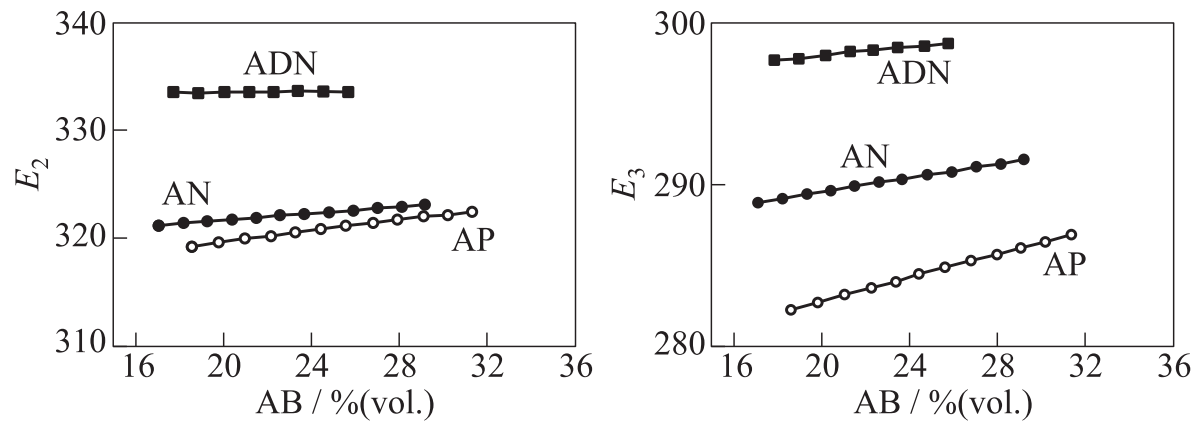

Figure 10 Ballistic efficiency of $\mathrm{AB}+$ oxidizer $+13 \%$ Be compositions

AN. In some cases, phase structure stabilization occurred at an additive content of only $3 \%-4 \%$. Some stabilizers are shown below:<smiles>O=c1[nH]c(=O)c2[nH]c(=O)[nH]c2[nH]1</smiles>

Uric acid<smiles>O=C1Nc2ccccc2C1=O</smiles>

Isatine<smiles>Nc1nc(O)c2nc[nH]c2n1</smiles>

Guanine<smiles>O=C1NC=CC([N+](=O)[O-])N1</smiles>

Nitrouracile

However, this stabilization is not complete: one phase transition, IV-II at $+50{ }^{\circ} \mathrm{C}$ or so persists. Nevertheless, this incomplete stabilization increases dramatically the mechanical stability of AN items at cyclic shock heating. Figure 14 demonstrates pressed AN tablets after such tests.

Note that the cracks arizing after 40 heating cycles (Fig. 14, right) are due to very fast cycling (in 20-30 $\mathrm{min}$ ) and therefore, wide range of temperature 

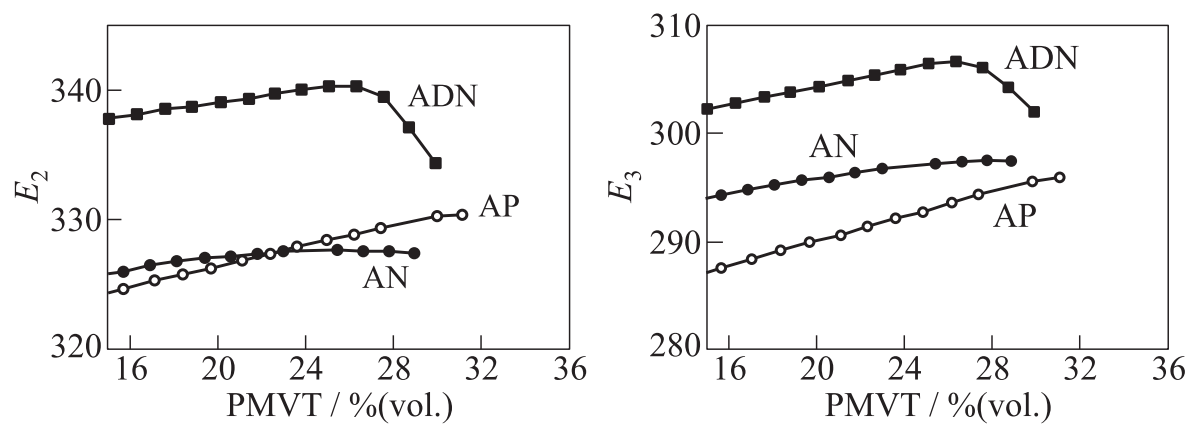

Figure 11 Ballistic efficiency of PMVT + oxidizer $+13 \%$ Be compositions
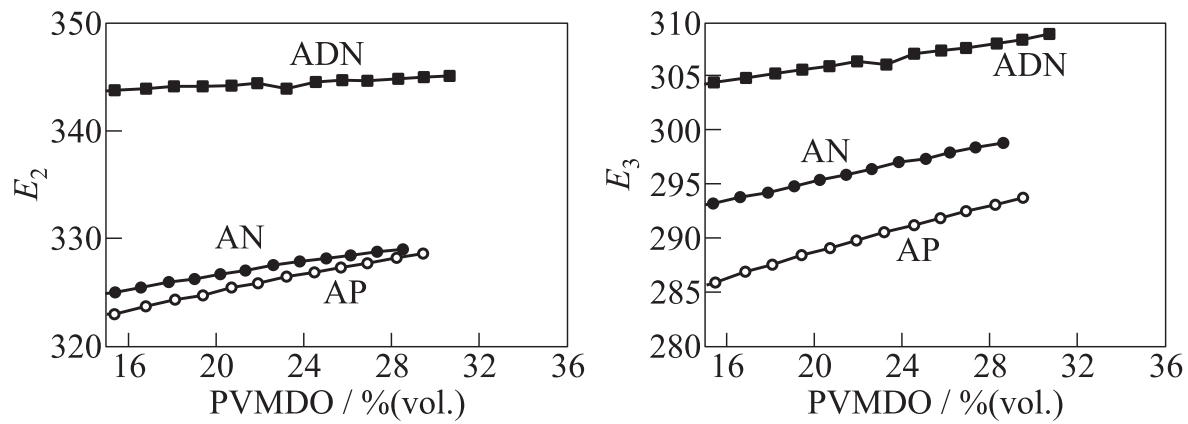

Figure 12 Ballistic efficiency of PVMDO + oxidizer $+13 \%$ Be compositions

Table 6 Calculated maximum attainable $E_{2}$ and $E_{3}$ for the compositions with $\mathrm{AB}$, oxidizer, and energetic component: $\mathrm{Al}$ (not exceeding 20\%), or Be (not exceeding $14 \%$ ), or $\mathrm{AlH}_{3}$ (not exceeding 25\%)

\begin{tabular}{|c|c|c|c|}
\hline Energetic component & Oxidizer & \multicolumn{2}{|c|}{$\mathrm{g}, \mathrm{cm}^{3}, \mathrm{~s}$} \\
\hline \multirow{3}{*}{$\mathrm{Al}$} & $\mathrm{AN}$ & 312 & 278 \\
\hline & $\mathrm{AP}$ & 321 & 286 \\
\hline & $\mathrm{ADN}$ & 332 & 294 \\
\hline \multirow{3}{*}{$\mathrm{Be}$} & $\mathrm{AN}$ & 329 & 297 \\
\hline & AP & 331 & 299 \\
\hline & $\mathrm{ADN}$ & 334 & 308 \\
\hline \multirow{3}{*}{$\mathrm{AlH}_{3}$} & $\overline{\mathrm{AN}}$ & $\overline{322}$ & 294 \\
\hline & $\mathrm{AP}$ & 333 & 300 \\
\hline & $\mathrm{ADN}$ & 338 & 306 \\
\hline
\end{tabular}



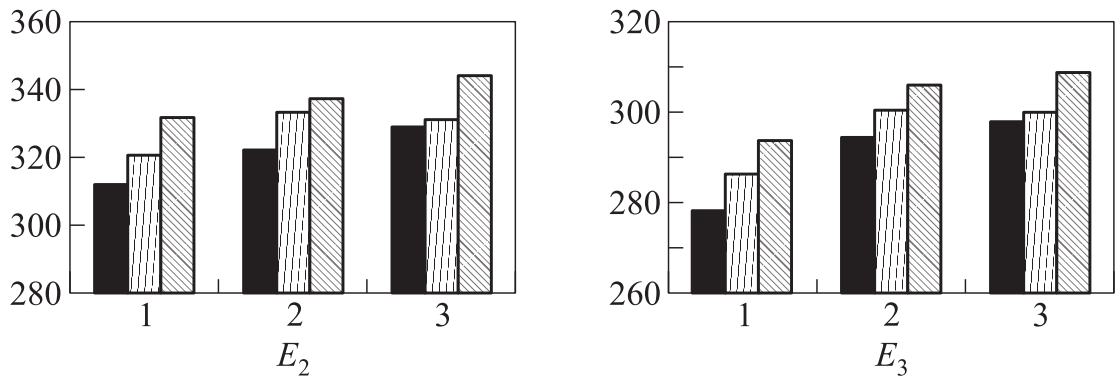

Figure 13 The calculated maximum attainable $E_{2}$ and $E_{3} .1$ - formulations with $\mathrm{Al} ;+-$ formulations with $\mathrm{AlH}_{3} ; 3$ formulations with Be. In each group the left bar corresponds to $\mathrm{AN}$, the middle - to $\mathrm{AP}$, and the right — to ADN

Table 7 Energy potential of compositions containing $18 \% \mathrm{AB}, 20 \% \mathrm{Al}$, $50 \%$ HMX, and $12 \%$ oxidizer

\begin{tabular}{lcccccc}
\hline Oxidizer & $I_{\mathrm{sp}}, \mathrm{s}$ & $\rho, \mathrm{g} / \mathrm{cm}^{3}$ & $T_{c}, \mathrm{~K}$ & $E_{1}$ & $\begin{array}{c}E_{2} \\
\mathrm{~g}, \mathrm{~cm}^{3}, \mathrm{~s}\end{array}$ & $E_{3}$ \\
\hline AP & 259.6 & 1.924 & 3790 & 384.4 & 337.3 & 295.9 \\
ADN & 261.9 & 1.905 & 3780 & 385.5 & 338.9 & 297.9 \\
AN & 262.3 & 1.895 & 3760 & 384.9 & 338.7 & 298.1 \\
\hline
\end{tabular}
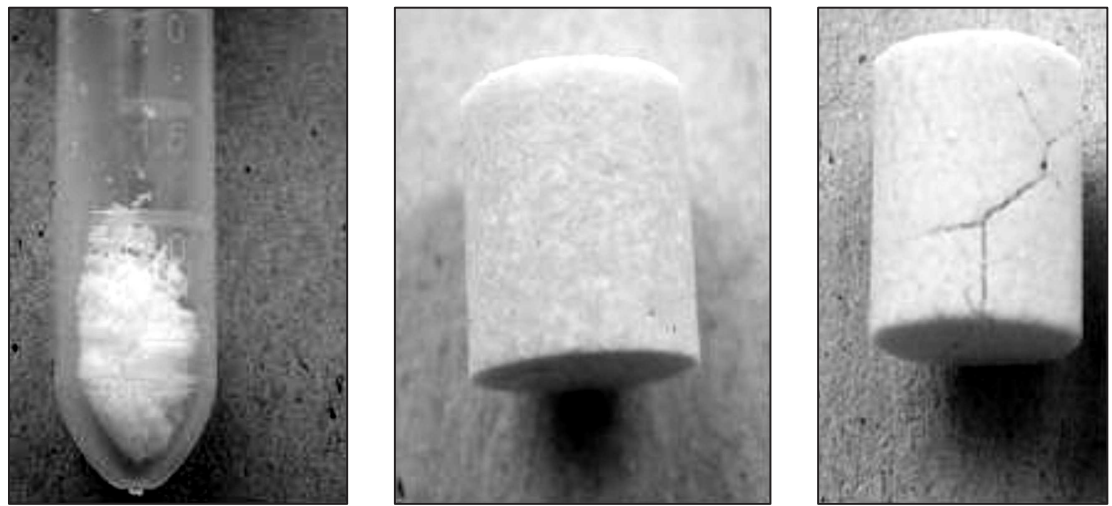

Figure 14 Samples of pressed AN tablets after multiple cyclic shock heating from -40 to $+90{ }^{\circ} \mathrm{C}$. Left to right: neat AN after two cycles; AN stabilized with uric acid after 10 cycles; and the latter after 40 cycles. Initial dimensions of the tablets: height $\sim 8-10 \mathrm{~mm}$, diameter $6.0 \mathrm{~mm}$ 
sweep in small samples. The tests were aimed at application of stabilized AN in gas-generating compositions for airbag inflators. The temperature storage conditions for SCPs are substantially milder. Additionally, the remaining IV-II phase transition occurs at $\sim 50$ rather than at the $32{ }^{\circ} \mathrm{C}$ IV-to-III phase transition often found for AN samples. Therefore, the gap between average storage temperature and phase transition has been substantially increased. The number of cases when the temperature could reach the phase transition point during years of storage has been reduced by orders of magnitude. Still, despite this optimistic assessment, a search for further phase stabilization of AN is necessary to get rid of any transition within the range of -40 to $+70{ }^{\circ} \mathrm{C}$. The work is underway at the Institute for Problems of Chemical Physics of the Russian Academy of Sciences.

\section{CONCLUDING REMARKS}

1. Despite the fact that $\mathrm{AN}$ is less energetic oxidizer compared to AP and ADN, it may compete them in cases when cost plays an important role, when environmental impact of combustion products is limiting (advantage over AP) and when storage in a wider temperature range is required (advantage over $\mathrm{ADN})$.

2. Upon addition of energetic components (Al, Be, hydrides), the ballistic efficiency of AN-based formulations increases more rapidly than for compositions using other oxidizers.

\section{REFERENCES}

1. Nechiporenko, G. N., and D. B. Lempert. 1998. An analysis of energy potentials of composite solid propellants containing beryllium or beryllium hydride as an energetic component. Chem. Phys. Rep. 17:1927-47.

2. Lempert, D. B., G. N. Nechiporenko, G. P. Dolganova, and L. N. Stesik. 1998. Specific impulse of optimized solid propellants (binder + metal + oxidizer) as a function of metal and oxidizer properties. Chem. Phys. Rep. 17:1547-56.

3. Rubtsov, Yu.I., A.I. Kazakov, L.P. Andrienko, I. I. Strizhevskii, and E. B. Moshkovich. 1987. Rate of thermodestruction of solid ammonium nitrate in presence of water and excess of nitric acid. Rus. J. Appl. Chem. 60:3-7.

4. Rubtsov, Yu. I., A. I. Kazakov, D. B. Lempert, and G. B. Manelis. 2006. Kinetic regularities of heat release in interaction of some organic compounds with ammonium nitrate. Propellants Explosives Pyrotechnics 31(6):421-34.

5. Campbell, A. N., and J. R. Campbell. 1946. Can. J. Res., Sect. B 24:93-108.

6. Lempert, D. B., G. N. Nechiporenko, N. I. Golovina, G. V. Shilov, G. P. Dolganova, and G. G. Nemtsev. 2004. Ammonium nitrate cocrystallites as a way to eliminate phase transitions in ammonium nitrate crystal lattice. 7th "Airbag-2004" (International) Proceedings. Karlsruhe, Germany. 44/1-44/4. 